E-ISSN : 2549-6581

DOI: 10.21776/ub.JOIM.2020.004.02.4

Artikel Hasil Penelitian

Diterima : 17 Juni 2019

Direview : 24 April 2020

Dimuat : Agustus - November 2020

\section{OPEN ACCESS}

Journal of Issues in Midwifer

\title{
Hubungan Status Gizi dan Konsumsi Junk Food dengan Menarche Dini Pada Remaja Awal (Studi Kasus di 3 Sekolah Dasar Kota Malang)
}

\author{
Nur Annisah Arifin ${ }^{1 *}$, Fatmawati $^{2}$, Ilmia Fahmi ${ }^{3}$ \\ ${ }^{1}$ Program Studi S1 Kebidanan, Fakultas Kedokteran, Universitas Brawijaya, Email: \\ Annisaharifin23@gmail.com, Tlp: +6283117738585 \\ 2 Program Studi S1 Kebidanan, Fakultas Kedokteran, Universitas Brawijaya \\ ${ }_{3}^{3}$ Program Studi S1 Gizi, Fakultas Kedokteran, Universitas Brawijaya
}

\begin{abstract}
In adolescence there is a process of maturation of the human reproductive organs and is known puberty. Puberty in women can be characterized by menstruation (menarche). Menarche is condition when women get a menstruation for the first time. The age of menarche can be influenced by several factors, genetics, nutrition, physical activity, environmental factors, the influence of the flow of communication, and globalization. This study aimd to determine the relationship of nutritional status and consumption of junk food with early menarche in young women in 3 elementary schools in Malang. The research design used was cross sectional. Samples from this study were from school students aged 10-12 years and who had undergone menstruation in 3 Malang elementary schools $(n=64)$ selected by purposive sampling method. The results of this study indicated the average age of menarche is $10.67 \pm 1.070$ years. From statistical tests with Spearmen correlation known that there was a relationship between nutritional status and early menarche with $p$-value $(<0,05)$, besides that there is also a relationship between consumption of junk food and early menarche with $p$-value $(>0,05)$. The conclusion obtained in this study is there is a relationship between nutritional status with early menarche. And there is no relationship between consumption of junk food with early menarche.
\end{abstract}

Key words: puberty, menarche, nutritional status, consumption of junk food, early adolescence

\section{ABSTRAK}

Pada masa remaja terjadi proses pematangan organ-organ reproduksi manusia biasa disebut masa pubertas. Pada perempuan, pubertas dapat ditandai dengan datangnya menstruasi (menarche). Menarche ialah saat seorang perempuan pertama kali mengalami menstruasi. Usia menarche dapat dipengaruhi oleh beberapa faktor yaitu genetika, nutrisi, aktivitas fisik, faktor lingkungan, pengaruh arus komunikasi, dan globalisasi. Tujuan dari penelitian ini adalah untuk mengetahui hubungan status gizi dan konsumsi junk food dengan usia menarche pada remaja putri di 3 sekolah dasar kota Malang. Desain penelitian yang digunakan adalah cross sectional. Sampel dari penelitian ini adalah siswi sekolah dasar yang berumur 10-12 tahun dan yang sudah menstruasi di 3 SD Kota Malang $(n=64)$ yang dipilih dengan metode purposive sampling. Hasil penelitian ini menunjukkan rata-rata usia menarche adalah 10,67 $\pm 1,07$ tahun. Dari uji statistik 
dengan korelasi Spearman ada hubungan antara status gizi dengan menarche dini dengan nilai $p$-value $(<0,05)$, selain itu tidak terdapat hubungan antara konsumsi junk food dengan menarche dini dengan nilai $p$-value $(>0,05)$. Kesimpulan dari penelitian ini adalah terdapat hubungan antara status gizi dengan menarche dini dan tidak terdapat hubungan antara konsumsi junk food dengan menarche dini.

Kata kunci: pubertas, menarche, status gizi, konsumsi junk food, remaja awal

*Korespondensi: Nur Annisah Arifin. Surel: annisaharifin23@gmail.com

\section{PENDAHULUAN}

Masa remaja adalah masamasa disaat anak mengalami peralihan dari masa sebelum remaja menuju ke dewasa baik dari secara fisik maupun psikologis ${ }^{(1)}$. Pada masa remaja organ reproduksi manusia mengalami proses pematangan dan sering disebut masa pubertas. Pubertas pada perempuan yaitu menstruasi (menarche)(2). Menarche adalah saat seorang perempuan pertama kalinya mengalami menstruasi ${ }^{(3)}$.

Usia menarche pada tiap individu berbeda-beda. Umumnya menarche berlangsung pada umur 12-14 tahun. Berdasarkan Riset Kesehatan Dasar (Riskesdes) tahun 2010 anak perempuan di Indonesia telah mengalami menarche pada usia dibawah 12 tahun ${ }^{(4)}$. Usia menarche dapat dipengaruhi oleh beberapa faktor yaitu genetika, nutrisi, aktivitas fisik, faktor lingkungan, pengaruh arus komunikasi, dan globalisasi. Penurunan usia menarche dapat berdampak negatif bagi kesehatan remaja putri, Mueller et al di Brazil pada tahun 2014 menyatakan bahwa usia menarche dini (<11 tahun) menjadi faktor resiko terjadinya diabetes dan penyakit kardiometabolik(5). Selain itu, menarche dini juga dapat menjadi faktor resiko terjadinya kanker payudara ${ }^{(6)}$.
Menurut Marmi (2013), pada usia remaja terjadi perubahan gaya hidup dan kebiasaan mencoba-coba hal baru, salah satunya mencobacoba makanan ${ }^{(7)}$. Remaja saat ini cenderung mengikuti pola makan teman sebayanya dan jenis makanan yang sesuai dengan perkembangan jaman. Banyaknya tayangan di media tentang berbagai makanan cepat saji (fast food), dapat menimbulkan rasa ingin tahu mereka untuk mencoba makanan tersebut. Remaja lebih menyukai makanan cepat saji karena penyajian yang cepat, dapat disajikan dan ditemukan dimana dan kapan saja, tempat dan makanan yang disajikan dianggap bersih, makanan bergengsi, makanan modern, dan makanan yang gaul bagi anak muda $^{(8)}$. Selain itu ketersediaan dan mudahnya akses untuk mendapatkannya berpengaruh besar terhadap kebiasaan mengonsumsi fast food.

Fast food adalah termasuk dalam golongan jenis makanan dan minuman yang rendah nutrisi yang biasa disebut junk food ${ }^{(9)}$. Kebiasaan mengonsumsi junk food dapat berpengaruh pada peningkatan gizi remaja karena kandungan dari junk food tersebut yang dapat mempengaruhi usia menarche. Peningkatan gizi berkaitan dengan keadaan lemak didalam tubuh yang mengakibatkan lemak menumpuk pada jaringan adiposa yang 
berkorelasi positif terhadap kadar leptin sehingga terjadi peningkatan kadar leptin. Apabila kadar leptin meningkat dapat mempengaruhi sekresi hormon GnRh dan dapat memproses pengeluaran $\mathrm{FSH}$ dan LH di ovarium dalam membangkitkan pembentukan folikel dan pembuatan estrogen sehingga mempercepat permulaan terjadinya menarche ${ }^{(10)}$. Penelitian yang dilakukan oleh Wulansari (2012) menunjukkan sebesar $60 \%$ dari seluruh responden mengalami menarche dini, yang disebabkan karena sangat sering mengkonsumsi junk food(11). Namun pada penelitian ini tidak menjelaskan frekuensi konsumsi yang dikatakan sering.

Sama halnya dengan penelitian yang telah dilakukan di Semarang yang menunjukkan prevalensi menarche dini sebesar $23,6 \%$ dengan hasil uji rendahnya asupan serat dan tingginya asupan lemak dan kalsium ${ }^{(12)}$. Beberapa penelitian menyatakan bahwa terdapat hubungan antara status gizi dengan usia menarche. Namun ada beberapa penelitian yang menolak pernyataan tersebut. Pada penelitian yang dilakukan oleh Chang Mo Oh et al (2012) di Korea menyatakan bahwa terdapat hubungan antara presentasi lemak dan IMT/U sebelum menarche dengan usia menarche dini ${ }^{13}$. Selain itu obesitas pada masa kanak-kanak merupakan faktor risiko terjadinya pubertas dini(14).

Studi lain yang telah dilakukan oleh Nugroho dkk di Bandar Lampung menyatakan bahwa terdapat hubungan antara status gizi dengan kejadian menarche dini(15). Namun penelitian yang dilakukan di Kuwait menunjukkan hasil yang berbanding terbalik antara usia menarche dengan indeks masa tubuh
(Al-Awadhi et al., 2013) dan Gopalakrishna et al (2016) yang melakukan penelitian di India juga menemukan tidak ada hubungan antara indeks massa tubuh dengan usia menarche ${ }^{(16,17)}$. Hal ini dipengaruhi oleh banyaknya faktor lain seperti asupan energi pada saat remaja terutama makanan yang mengandung hormon estrogen dan antiestrogen, latar belakang etnis dan budaya, status sosial keluarga, dan gaya hidup yang juga berperan penting dalam menentukan usia menarche.

Berdasarkan data diatas masih terdapat kontradiksi dari hasil penelitian mengenai status gizi dengan usia menarche, maka peneliti berminat untuk mengetahui lebih jauh mengenai status gizi dengan usia menarche dan mengaitkannya dengan konsumsi junk food pada remaja putri di Kota Malang. Peneliti memilih SDN Tlogomas 2 No. 248, SDN Merjosari 1, dan SD Brawijaya Smart School dengan alasan letaknya berada ditengah kota, dekat dengan pusat perbelanjaan, mudah dijangkau peneliti, serta belum pernah dilakukan penelitian sebelumnya di 3 lokasi tersebut.

\section{METODE PENELITIAN Desain Penelitian}

Desain penelitian yang digunakan adalah cross sectional. Desain penelitian ini akan mengkaji hubungan variabel bebas yaitu status gizi dan konsumsi junk food, dan variabel terikatnya yaitu usia menarche yang diukur dalam satu waktu.

\section{Sumber Data}

Sumber data diperoleh dari lembar kuesioner usia menarche, food questionnaire, form food frequency questionnaire yang telah 
dimodifikasi pada penelitian sebelumnya dan pengukuran berat badan dan tinggi badan.

\section{Sasaran Penelitian}

Seluruh siswi kelas $4-6$ sekolah dasar yang berumur 10-13 tahun dan yang sudah mendapat menstruasi di 3 SD (Kota Malang). Sejumlah 64 siswi menjadi sampel pada penelitian ini dengan menggunakan teknik purposive sampling.

\section{Pengembangan Instrumen dan Teknik Pengumpulan Data}

Penelitian ini menggunakan instrumen yaitu lembar skrining untuk menjadi sampel penelitian, lembar kuesioner usia menarche untuk mengetahui usia menarche, food questionnaire, form food frequency questionnaire yang telah dimodifikasi pada penelitian sebelumnya dan pengukuran berat badan dan tinggi badan.

\section{Teknik Analisis Data}

Uji hipotesis dilakukan dengan teknik korelasi menggunakan uji statistik korelasi Spearman dan diolah menggunakan program SPSS 16. Penelitian ini sudah melewati proses ethucal clearence dan dinyatakan telah laik etik oleh komisi etik penelitian kesehatan Fakultas Kedokteran Universitas Brawijaya Malang No. 339/EC/KEPK-S1$\mathrm{KB} / 12 / 2018$.

\section{HASIL PENELITIAN}

\section{Analisis Univariat}

Tabel 1. Karakterisitik Responden berdasarkan Kelas dan Usia

\begin{tabular}{|c|c|c|c|c|c|}
\hline \multirow{2}{*}{ Usia Responden } & \multicolumn{3}{|c|}{ Kelas } & \multirow{2}{*}{ Total } & \multirow{2}{*}{$f(\%)$} \\
\hline & Kelas 4 & Kelas 5 & Kelas 6 & & \\
\hline 10 & 3 & 1 & 1 & 5 & 7,8 \\
\hline 11 & 0 & 7 & 23 & 30 & 46,9 \\
\hline 12 & 0 & 1 & 28 & 29 & 45,3 \\
\hline Total & 3 & 9 & 52 & 64 & 100 \\
\hline
\end{tabular}

Berdasarkan Tabel 1, diperoleh informasi jumlah responden yang Sebagian besar responden 46,9\% mengikuti penelitian adalah 64 siswi.

Tabel 2. Distribusi Status Gizi Remaja Putri

\begin{tabular}{lll}
\hline Status Gizi & $\mathrm{n}$ & $\mathrm{f}(\%)$ \\
\hline Normal & 17 & 27 \\
\hline Overweight & 34 & 53 \\
\hline Obesitas & 13 & 20 \\
\hline Total & 64 & 100 \\
\hline
\end{tabular}


Berdasarkan Tabel 2, dapat remaja putri yaitu sebesar 53\% diketahui bahwa sebagian besar mempunyai status gizi overweight.

Tabel 3. Jenis junk food yang sering dikonsumsi remaja putri

\begin{tabular}{|c|c|c|c|c|c|c|}
\hline & $\begin{array}{l}\text { Tidak } \\
\text { Pernah }\end{array}$ & $\begin{array}{c}1- \\
2 x / \text { minggu }\end{array}$ & $\begin{array}{c}3- \\
4 x / \text { minggu }\end{array}$ & $\begin{array}{c}5- \\
6 x / \text { minggu }\end{array}$ & 1x/hari & $\geq 2 x /$ hari \\
\hline & $f(\%)$ & $f(\%)$ & $f(\%)$ & $f(\%)$ & $f(\%)$ & $f(\%)$ \\
\hline Burger & 26.6 & 67.2 & 0.0 & 3.1 & 3.1 & 0.0 \\
\hline Pizza & 34.4 & 59.4 & 3.1 & 3.1 & 0.0 & 0.0 \\
\hline $\begin{array}{l}\text { Kentang } \\
\text { Goreng }\end{array}$ & 7.8 & 32.8 & 34.4 & 15.6 & 6.3 & 3.1 \\
\hline Kripik Kentang & 1.6 & 23.4 & 40.6 & 23.4 & 9.4 & 1.6 \\
\hline $\begin{array}{c}\text { Ayam Goreng } \\
\text { Tepung }\end{array}$ & 0.0 & 21.9 & 37.5 & 32.8 & 3.1 & 4.7 \\
\hline Gorengan & 14.1 & 32.8 & 23.4 & 12.5 & 12.5 & 4.7 \\
\hline Tempura, Sosis & 31.3 & 20.3 & 26.6 & 10.9 & 6.3 & 4.7 \\
\hline $\begin{array}{l}\text { Minuman } \\
\text { Berperisa }\end{array}$ & 17.2 & 25.0 & 29.7 & 18.8 & 7.8 & 1.6 \\
\hline $\begin{array}{l}\text { Minuman } \\
\text { Bersoda }\end{array}$ & 17.2 & 40.6 & 15.6 & 20.3 & 3.1 & 3.1 \\
\hline Es Campur & 7.8 & 34.4 & 37.5 & 10.9 & 4.7 & 4.7 \\
\hline Sempol, Cilok & 12.5 & 32.8 & 31.3 & 17.2 & 3.1 & 3.1 \\
\hline Sate Telur & 20.3 & 18.8 & 34.4 & 17.2 & 4.7 & 4.7 \\
\hline $\begin{array}{l}\text { Minuman } \\
\text { Kemasan }\end{array}$ & 15.6 & 23.4 & 35.9 & 17.2 & 6.3 & 1.6 \\
\hline Roti Bakar & 12.5 & 29.7 & 31.3 & 23.4 & 3.1 & 0.0 \\
\hline Susu Kemasan & 1.6 & 12.5 & 48.4 & 23.4 & 7.8 & 6.3 \\
\hline Mie Instan & 15.6 & 9.4 & 42.2 & 25.0 & 6.3 & 1.6 \\
\hline Kebab & 39.1 & 46.9 & 9.4 & 3.1 & 0.0 & 1.6 \\
\hline $\begin{array}{l}\text { Berdasar } \\
\text { menggamba } \\
\text { junk food ya } \\
\text { Jenis junk } \\
\text { dikonsumsi } \\
\text { tepung dan }\end{array}$ & $\begin{array}{l}\text { an } \\
\text { kan perb } \\
\text { foring } \\
\text { food y } \\
\text { dalah as } \\
\text { usu kem }\end{array}$ & $\begin{array}{l}\text { Del } 3, \\
\text { daan jenis } \\
\text { konsumsi. } \\
\text { ig sering } \\
\text { m goreng } \\
\text { san dilihat }\end{array}$ & \multicolumn{4}{|c|}{$\begin{array}{l}\text { dari jumlah responden yang tidak } \\
\text { pernah mengkonsumsi kripik } \\
\text { kentang yaitu } 1 \text { orang, dan } \\
\text { seluruh responden mengkonsumsi } \\
\text { ayam goreng tepung selama } 3 \\
\text { bulan terakhir. }\end{array}$} \\
\hline
\end{tabular}

\section{Frekuensi Konsumsi Junk Food}

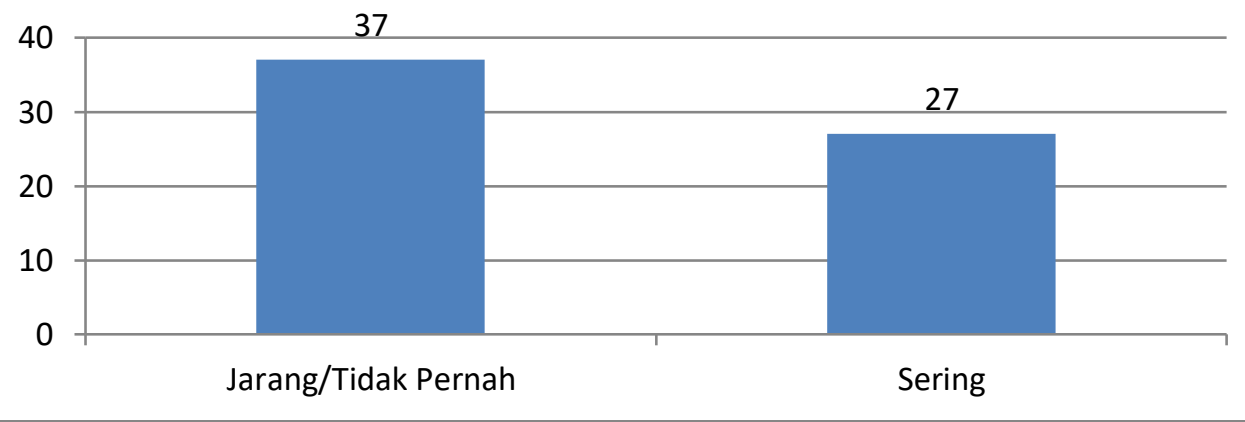

Gambar 1. Frekuensi Konsumsi Junk Food 
Berdasarkan Gambar 1, dapat jarang/ tidak pernah mengkonsumsi diketahui bahwa sebagian responden junk food.

Tabel 4. Karakteristik Responden terkait Junk Food

\begin{tabular}{llll}
\hline & Karakteristik & $\mathrm{f}(\%)$ \\
\hline 1. & Pengertian & Siap Saji/ Cepat Saji & 100 \\
\hline 2. Mulai Konsumsi & TK & 37,5 \\
& & Kelas 1 & 29,7 \\
& & Kelas 2 & 32,8 \\
\hline 3. Jenis & Ayam Krispi & 31,2 \\
& Gorengan & 31,2 \\
& Cilok & 21,9 \\
& & Kentang Goreng & 15,6 \\
\hline \multirow{2}{*}{ Alasan } & Ibu Tidak Masak & 40,6 \\
& & Sedang Ingin & 28,1 \\
& & Rasanya Enak & 31,2 \\
\hline 5. Lokasi/ Tempat Membeli & PKL & 29,7 \\
& Kantin & 23,4 \\
& Rumah Makan & 46,9 \\
\hline
\end{tabular}

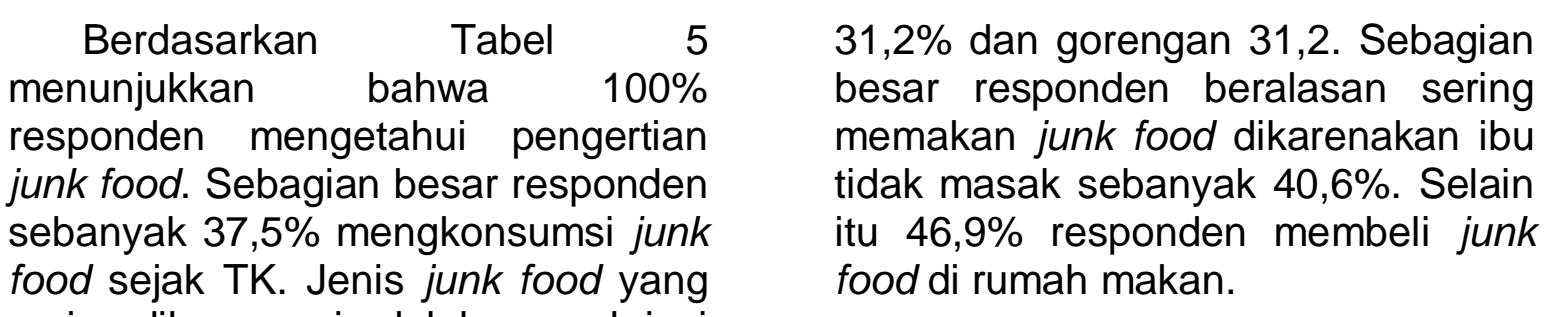
sering dikonsumsi adalah ayam krispi

\section{Analisis Bivariat}

Tabel 6. Hasil Uji Korelasi Spearman

\begin{tabular}{lcc}
\hline Hubungan & $r_{\text {hitung }}$ & $p$-value \\
\hline Status Gizi dengan Menarche Dini & $-0,824$ & 0,000 \\
Konsumsi Junk Food dengan Menarche & 0,581 & 0,070 \\
Dini & & \\
\hline
\end{tabular}

Berdasarkan Tabel 6 , hasil uji korelasi Spearman status gizi berhubungan dengan usia menarche ditemukan nilai $r_{\text {hitung }}$ sebesar $-0,824$ dengan $p$-value 0,000 yang berarti ada hubungan yang berarti antara status gizi dengan menarche dini. Sedangkan hasil uji korelasi
Spearman hubungan konsumsi junk food dengan menarche dini ditemukan nilai $r_{\text {hitung sebesar } 0,581}$ dengan $p$-value 0,070 yang berarti tidak ada hubungan yang berarti antara konsumsi junk food dengan menarche dini. 


\section{PEMBAHASAN}

Dari hasil uji statistik dengan uji korelasi spearman terdapat hubungan antara status gizi dengan menarche dini yang ditunjukkan dengan nilai sig $=0,000(<0,05)$ dan tidak terdapat hubungan yang signifikan antara konsumsi junk food dengan menarche dini nilai sig = $0,07 \quad(>0,05)$. Terdapat beberapa penelitian yang sesuai dengan penelitian ini. Penelitian yang dilakukan oleh Nugroho 2015 menunjukkan bahwa remaja yang memiliki asupan lemak lebih dan dengan status gizi lebih (overweight dan obesitas) cenderung mengalami menarche dini ${ }^{(15)}$. Kadar lemak pada tubuh dapat mempengaruhi waktu timbulnya pubertas tingginya kadar lemak berpengaruh terhadap meningkatnya kadar leptin. Leptin berperan dalam maturasi hipotalamus saat pubertas ${ }^{(18)}$.

Penelitian lain yang dilakukan oleh Wulansari (2012) menunjukkan siswi SD di Surakarta yang mengonsumsi junk food dalam kategori sering didapatkan mengalami menarche dini(11). Berdasarkan hasil wawancara menunjukkan bahwa frekuensi rata-rata konsumsi junk food pada remaja putri adalah 1-2 x/ minggu. Hal ini sejalan dengan penelitian Deni dan Dwiriani (2009) yang menunjukkan bahwa anakanak sekolah mengkonsumsi junk food 1-3x/ minggu terutama saat hari libur ${ }^{(19)}$. Rendahnya aktitas fisik juga menyumbangkan pengaruh yang besar terhadap peningkatan gizi ${ }^{(20)}$.

Peningkatan gizi lebih berhubungan dengan kondisi lemak didalam tubuh yang mengakibatkan lemak menumpuk pada jaringan subkutan yang berkorelasi positif terhadap kadar leptin sehingga terjadi peningkatan kadar leptin. Apabila kadar leptin meningkat dapat mempengaruhi sekresi hormon GnRh dan dapat memproses pengeluaran FSH dan $\mathrm{LH}$ di ovarium dalam membangkitkan pembentukan folikel dan pembuatan estrogen sehingga mempercepat permulaan terjadinya menarche ${ }^{(10)}$.

\section{SIMPULAN}

Status gizi dapat mempengaruhi terjadinya menarche pada remaja putri dimana status gizi lebih akan menyebabkan kejadian menarche yang lebih awal. Untuk penelitian selanjutnya disarankan untuk meneliti lebih lanjut mengenai pola konsumsi junk food terutama bila pola tersebut telah dilakukan sejak TK atau sebelumnya, serta faktor lain yang mempengaruhi usia menarche misalnya faktor genetik, aktifitas fisik, lingkungan, pengaruh arus komunikasi dan globalisasi. Bagi pihak sekolah disarankan untuk memperkenalkan pendidikan kesehatan reproduksi dan gizi kepada siswa, memperhatikan makanan dan jajanan yang dijual di kantin sekolah agar makanan yang dijual memiliki nilai gizi yang seimbang.

\section{DAFTAR PUSTAKA}

1. Utami, P. dan Puspaningtyas, D.E. 2013. The Miracle Of Herbs. Jakarta: Agromedia.

2. Kumalasari, I. dan Andhyantoro, I. 2014. Kesehatan Reproduksi untuk Mahasiswa Kebidanan Dan Keperawatan. (Cetakan ke-3) Jakarta: Salemba Medika. 
3. Diah, Aryulina, dkk. 2006. Biologi SMA dan MA untuk Kelas XI. Jakarta: PT. Gelora Aksara Pratama.

4. Riset Kesehatan Dasar. 2010. Badan Penelitian Dan Pengembangan Kesehatan, Riset Kesehatan Dasar. Jakarta: Kementrian Kesehatan RI.

5. Muller et al. 2014. Earlier Age at Menarche is associated with higher diabetes risk and cardioametabolic disease risk factors in Brazialian adults: Brazilian Longitudinal Study Of Adulth Health (ELSA-Brasil). Cardiovascular Diabetology, 13:22

6. DH Morris, et al. 2010. Determinants of age at menarche in the UK: analyses form the Breaktrough Generations Study. Brirtish Journal of Cancer 103, 1760-1764

7. Marmi. 2013. Gizi Dalam Kesehatan Reproduksi. Yogyakarta: Pustaka Pelajar

8. Lutfi, S. 2011. Makan Teratur Mahasiswa Tingkat Akhir. Dikutip dari http://lutiblurry.com/ (diakses 18 Oktober 2018).

9. Wulan, Reni Sari. 2008. Dangerous Junk Food. Yogyakarta : $\mathrm{O} 2$

10. Maditias, G.D.P. 2015. Konsumsi Junk Food dan Pubertas Dini. Lampung: Universitas Lampung

11. Wulansari, dkk. 2012. Hubungan Konsumsi Junk Food dan Media Informasi Terhadap Menarche Dini Pada Siswi Sekolah Dasar Di Surakarta. Surakarta: Universitas Muhammadyah Surakarta

12. Susanti, et al. 2012. Faktor risiko kejadian menarche dini pada remaja SMP N 30 Semarang. Semarang: Universitas Diponegoro.
13. Chang Mo Oh, et al. 2012. Relationship Between Body Mass Index and Early Menarche of Adolescent Girls in Seoul. J Prev Med Public Health 45, 227-234

14.C. Currie, et al. 2012. Is Obesity at Individual and National Level Associated With Lower Age at Menarche? Evidence From 34 Countries in the Health Behaviour in School-aged Children Study. Journal of Adolescent Health 50, 621-626

15. Nugroho, dkk. 2015. Hubungan Antara Zat Gizi dan Status Gizi dengan Kejadian Meanrche Dini pada Siswa SD Negeri 2 di Kota Bandar Lampung. Bandar Lampung: Poltekkes Kemenkes Tanjungkarang

16. Al-Awadhi, Nora et al. 2013. Age At Menarche And Its Relationship To Body Mass Index Among Adolescent Girls In Kuwait. BMC Public Health, 13:29

17. Gopalakrishna, et al. 2016. Association of age at menarche with body mass index and waisthip ratio. International Journal of Medical Science and Public Health Vol 5

18. White, BA \& Susan, P. 2013. Endocrine and Reproductive Physiology. Philadelphia: ELSEVIER MOSBY

19. Deni dan Dwiriani, C.M. 2009. Pengetahuan gizi, aktifitas fisik, konsumsi snack dan pangan lainnya pada murid sekolah dasar di Bogor yang berstatus gizi normal dan gemuk. Jurnal Gizi dan Pangan. Juli 2009;4(2): 9196.

20.Klein S, et al. 2007. Waist Circumferance and Cardiometabolic Risk: A Consensus Statement from Shaping America's Health: Association for Weight 
90 Journal of Issues in Midwifery, Vol. 4 No. 2 Bulan Agustus - November 2020, Halaman 82-90
Management and Obesity
Prevention: NAASO, The Obesity
Society. The American Society for
Nutrition and The American
Diabetes Association Obesity, 15
(5):1061-7. 